\title{
ZARELA. UNA HISTORIA FEMINISTA NOVELA DE LEONOR ESPINOZA DE MENÉNDEZ: SIN EDUCACIÓN LA MUJER NO AVANZA
}

\author{
LEONOR ESPINOZA DE MENÉNDEZ'S \\ ZARELA. A FEMINIST STORY: \\ WITHOUT EDUCATION WOMAN DOES NOT ADVANCE
}

Lady Rojas Benavente ${ }^{1}$

\begin{abstract}
RESUMEN
Esta investigación se centra en la novela de Leonor Espinoza de Menéndez, Zarela. Una historia feminista (¿1915?) que plantea la necesidad de cambiar la condición femenina en el Perú de principios del siglo XX a través del reconocimiento legal de los derechos cívicos, educativos y laborales de las mujeres. Las cuestiones del género, de las representaciones ideológicas de los personajes masculinos y femeninos y de las relaciones abusivas permiten entender mejor el contexto tradicional y misógino de la sociedad que se amparaba en sus instituciones estatales, jurídicas y culturales para mantener el statu quo y las diferencias sociales y sexuales. La escritora Espinoza pone el énfasis en la necesidad de la educación de la mujer para que pueda desarrollarse y desempeñarse en el trabajo de manera autónoma e independiente. Su feminismo de igualdad aboga por los cambios urgentes.
\end{abstract}

\section{Palabras clave}

Novela feminista, condición de las mujeres, reivindicaciones por la educación, el trabajo y la autonomía

\section{ABTRACT}

This research focuses on Leonor Espinoza de Menéndez's novel, Zarela. A feminist story (1915?) raising the need to change the status of women in the early 20th century in Peru through legal recognition of civic, educational and labour rights of women. The gender issues, ideological representations of male and female characters and abusive relationships help understand the traditional and misogynist society's context that was backed by State, legal and cultural institutions in order to maintain the status quo and social and sexual differences. The writer Espinoza emphasizes the need for education of women so that she can develop and play a role at work autonomously and independently. Her equality feminism calls for urgent changes.

\section{Keywords}

Feminist novel, feminine condition, wrights of education, work and autonomy

\section{INTRODUCCIÓN}

Las escritoras, pedagogas y periodistas, especialmente de la generación de 1870 en el Perú, se preocuparon por las desigualdades de género incrementadas por la falta de acceso a la educación y a la vida cívica, la discriminación sexual, las injusticias sociales y la violencia doméstica que se infringía contra muchas mujeres, e iniciaron un proceso

\footnotetext{
Doctora en Literatura hispánica, especializada en cuestiones de género y feminismo. Catedrática de planta de la Universidad Concordia, Montreal, Canadá.
} 
de cuestionamiento en el campo cultural $e$ ideológico sobre la posición de la población femenina en una nación que se mostraba antidemocrática y excluyente ${ }^{2}$. Entre las novelistas de principios del siglo XX destaca en el bastión sur y progresista de Arequipa, Leonor Espinoza de Menéndez, una de las intelectuales que continúa la defensa de las mujeres, exige el derecho a la educación y brega en favor de otros derechos equitativos en su obra Zarela. Una historia feminista (¿1915?).

La pedagoga y crítica literaria Elvira García y García en su libro, La mujer a través de los siglos. Serie historiada de estudios y observaciones, presenta con agudeza la labor transformadora de Espinoza, "Hacia el año 1908 se dedicó a escribir, a favor de la actividad social de la mujer, tema que ha tratado siempre con cariño e interés, trabajando con todo afán, para que se cambie la situación de esclava del hombre en que vive hasta hoy, no obstante de llamarse este siglo, el del progreso" (García y García 1925, p. 147). García y García continúa su aprecio, "últimamente ha dirigido sus pasos a la creación de la novela local, y el primer ensayo Zarela, es un esfuerzo muy loable..." y luego recomienda a Espinoza, "aunque sería de desear, que al defender la escuela feminista, trate a la mujer, desde un punto de vista más alto, prescindiendo de la chismosa, frívola y laberintera, para escoger, entre el grupo, que le sirve de estudio, a aquélla que se pueda exhibir como un modelo edificante" (García y García 1925, p. 148). La novela realista de Espinoza no toma en cuenta la propuesta de García y García como lo subrayo en esta investigación porque su proyecto consistía en hacer en ocho capítulos, una radiografía social, cultural, ideológica, económica y moral de través de los personajes femeninos convencionales y las transformaciones que se podrían lograr con su protagonista feminista Zarela.

El prólogo de la novela, "A modo de heraldo" hecho por Francisco Mostajo en el momento de la publicación destaca: primero, "la heroicidad" de la escritora "con una conciencia de haber servido a la causa de vuestro sexo $i$ de ser zapadora de un ideal que triunfará" cuando exista "amor i justicia verdaderos", "para dedicarse a la amena literatura en estos míseros medios de a centavo" porque los críticos calificados de "cretinos", "cacúmenes" y "palurdos" no toleran que una mujer intelectual contravenga con su posición igualitaria "a la prosaica ocupación de zurcir $i$ al rol de preciosa gatita de la adámica sensualidad." Claramente el crítico traza los modelos femeninos en función de su papel doméstico o de femme fatale frívola en un medio donde gobierna "el fósil de los viejos prejuicios" que se manifiestan en "hostiles erizaciones" y "mentiras convencionales." En segundo lugar, Mostajo afirma, "La Sra. Leonor Espinoza de Menéndez es hija del propio esfuerzo" (Mostajo en Espinoza M. L. ¿1915? p. I-II), que señala el trabajo y la profesión de escritora auto-didacta.

Otras dos críticas contemporáneas evalúan la novela de Espinoza. Primero, Isabelle Tauzin-Castellanos en su artículo, "Zarela: La emergencia del feminismo en Arequipa" (1999), estudia la condición femenina y su proceso de desarrollo tanto intelectual como cotidiano y enfatiza las dificultades de la mujer en su papel auxiliar, antagonista o protagonista de acuerdo al estado civil: la casada estéril, la madre heroica frente al destino nacional pero dependiente del marido, la esposa violentada, la madre monoparental, la solterona cruel y la feminista. Segundo, Giovanna Minardi resume Zarela en su texto panorámico, "La narrativa peruana en el Perú del siglo XIX" (2001).

Esta pesquisa tiene el propósito de captar las estrategias feministas y retóricas que usa Espinoza, primero, para denunciar las representaciones falsas, las divisiones sexuales y los estereotipos sexistas, y segundo, para corregir los abusos infligidos a la mujer por una sociedad patriarcal en la que persisten

\footnotetext{
2 Dos libros fundamentales sobre las escritoras del XIX son: de Maritza Villavicencio, Del silencio a la palabra. Mujeres peruanas en los siglos XIX-XX (1992) y de Francesca Denegri, El abanico y la cigarrera. La primera generación de mujeres ilustradas en el Perú (1996). Fuera del Perú es esencial, La escritura (casi) invisible. Narradoras hispanoamericanas del siglo XIX de Remedios Mataix (2003).
} 
las leyes arcaicas, prácticas y jerarquías neocoloniales que, al interior de las parejas, conceden el mando absoluto al hombre e imponen la obediencia ciega a la esposa. La hipótesis de este ensayo es que la novelista Espinoza narra esa dinámica asimétrica y expone el maltrato para que se lo corrija, por eso reclama la justa igualdad entre los seres de ambos sexos. La obra feminista despierta el interés de los lectores contemporáneos porque expone las relaciones matrimoniales en cuyo desenvolvimiento se involucran además de los esposos, las mujeres tradicionales y pasivas, consciente o inconscientemente. Para enmendar las dificultades de la condición femenina la autora propone, primero, la educación formal y, segundo el derecho de la mujer al trabajo. Ambos recursos resultan armas imprescindibles para la consecución de su independencia económica y su desarrollo integral, humano y cultural. Sin embargo la nación también debe facilitar el pasaje de la mujer ignorante a la mujer ilustrada con leyes acordes a sus necesidades y una infraestructura educacional que favorezca su ingreso a los centros superiores del saber.

\section{EL CONTEXTO HISTÓRICO DEL PERÚ A FINES DEL SIGLO XIX Y PRINCIPIOS DEL SIGLO XX}

Es importante antes de explorar el discurso y las prácticas misóginas en la novela, entender el contexto histórico en el que se produce, en ese sentido, examinaremos ciertas propuestas de escritoras feministas en sus debates en el campo del ensayo. Contamos en el Perú con pensadoras críticas que propusieron, desde fines del siglo XIX, transformaciones para que se aboliera el servilismo doméstico, se favoreciera la autonomía de la mujer y se la considerada como sujeto histórico, poniendo énfasis en remediar las trabas que los impedían ${ }^{3}$. En pleno siglo XX, las feministas Zoila Aurora Cáceres y María Jesús Alvarado iniciaron de manera sistemática la lucha por la igualdad de géneros en el Perú, la primera imbuida de su misión apostólica y la segunda de su fervor feminista.

En primer lugar, Cáceres propicia en su libro de feminismo, Mujeres de ayer y de hoy, las bases de un sistema educativo que dé una formación de base y de instrucción a las jóvenes peruanas para que adquieran, como las argentinas, un sentido práctico de la vida familiar y superen la "naturaleza esencialmente sentimental y romántica, en ella no existe un espíritu emprendedor ni de grandes alientos, su vida la consagra al hogar, del cual, más que mujer, es ángel, pues su abnegación para con el esposo no tiene límites, y sobretodo para con sus hijos, de los que se convierte en mártir" (Cáceres Z, A. 1909, p. 188). Cáceres menciona otro trazo de las peruanas "el misticismo fervoroso" que la provee de "un inagotable tesoro de abnegación, capaz de ir hasta el heroísmo" (Cáceres Z, A. 1909, p. 189). Del primer problema culpa a la sociedad patriarcal que "descuida Ś...S el procurarle la instrucción superior" y del segundo apunta a la "nación en donde se haya prescindido de la segunda enseñanza para la mujer, y más lamentable es esta omisión justamente en Lima" (Cáceres Z, A. 1909, p. 204).

Para superar las carencias al interior del hogar y de la sociedad, Cáceres presenta el programa del Centro Social de Señoras que ella funda en 1908 con Matilde Guerra de Miró Quesada "con el fin de establecer un Liceo para Señoritas, una Sección Preparatoria de Primera Enseñanza, una Sección Comercial, una Escuela Doméstica y otros anexos" (Cáceres Z, A. 1909, p. 204). Con argumentos racionales, psicológicos, sociales y apoyándose en la Pedagogía Moderna y en el ejemplo de "países del mundo civilizado" justifica la necesidad de sacar a la mujer peruana de la "ignorancia, que la inhabilita para encontrar medio apropiado a su condición social, capaz de procurarle

En el campo de la educación léase: de Tauzin-Castellanos, Isabelle (2004) "La educación femenina en el Perú del siglo XIX". En Aurora Marrou Roldán, Historia de la educación peruana y latinoamericana, pp. 92-102. De Rojas Benavente, Lady (2010) Canto poético a capella de las escritoras peruanas de 1900 a 1960, la parte 2 del I capítulo intitulado, "La educación de la población femenina del Perú, la demografía y la prostitución", pp. 74-99. De Guardia, Sara Beatriz (Mayo 2013) "Imaginar la mujer. Mercedes Cabello y la educación femenina". En CEMHAL, Revista historia de mujeres. Lima, 14.150. http://webserver.rcp.net.pe/cemhal/revista3.html 
los recursos indispensables para la vida" (Cáceres Z, A. 1909, p. 205). No obstante, aclara que dicha formación intelectual no pretende "prodigar conocimientos tan vastos como los que abarcan los colegios de varones en la enseñanza secundaria; ni preparar señoritas para que lleguen al doctorado" (Cáceres Z, A. 1909, p. 206). La educación gratuita cuidará su futuro papel de esposa católica dentro del hogar4. Es evidente que el desarrollo de aptitudes profesionales, comerciales y domésticas procura en ese contexto restringido un aliciente para "triunfar en la vida... y levantarle el espíritu y enseñarle que las señoritas, en el Perú, pueden trabajar como lo hacen las de otros países... para cumplir de esta manera la misión que las exigencias de la vida moderna les impone" (Cáceres Z, A. 1909, p. 212-13). A pesar del encuadramiento latinoamericano y mundial, Cáceres sostiene que la educación y el trabajo procuran la autonomía económica y eso significa un gran paso hacia la libertad.

En segundo lugar y de manera más radical, María Jesús Alvarado ofrece un programa concreto de educación, trabajo y de igualdad jurídica, en su documento histórico y ensayo filosófico-literario, "El Feminismo", presentado el 28 de octubre de 1911 en la Biblioteca Nacional con el propósito, entre otros, de reformar el Código Civil. Luego funda el movimiento Evolución Femenina en 1914 que realiza acciones concretas frente al poder estatal para que reconozca legalmente los derechos a la educación, el trabajo y la incorporación de la mujer a la esfera pública mediante el voto $^{5}$. Ambas escritoras, Cáceres y Alvarado, lidian en la arena pública para que el estado tome cartas en el asunto y legisle en favor del avance integral de las mujeres. De acuerdo a Alvarado, las leyes atrasadas constituyen uno de los frenos principales que impide que la sociedad acepte las potencialidades intelectuales, racionales y laborales, y causa la ignorancia, dependencia y marginalidad de las mujeres. Su visión feminista más liberal que la de Cáceres y su movilización constante ayudan a que la legislación peruana cambie poco a poco y reconozca sus derechos.

\section{LAS REPRESENTACIONES DUALISTAS DE LAS MUJERES}

La novela Zarela expone justamente las dificultades de la sociedad legalista y misógina que no acepta las innovaciones educativas e ideológicas que las feministas ponen en práctica en Lima. En ese sentido, Espinoza juzga severamente las leyes del Código Civil napoleónico de 1851 que imponían la dependencia de las mujeres con respecto a los hombres, al punto de considerarlas en el mismo nivel que "los hijos menores... y los incapaces." En una época dominada por el poder absoluto de los hombres y de ciertas instituciones culturales, que se transmite a través de prejuicios sexuales y sexistas, y un código de convencionalismos sociales; el estado político ignoró los derechos humanos de la mitad de la población marginada. Por esas razones, la obra de Espinoza, Zarela clasifica las representaciones femeninas en dos grupos y se centra en el conflicto narrativo entre la mujer tradicional que ocupa más de cuatro primeros capítulos de la obra y la mujer moderna a través de las imágenes socioculturales que se fomentan de ellas. Es claro que el paralelo propicia el triunfo de la mujer instruida y científica en los capítulos tercero, sexto, séptimo y octavo, como el primer paso en el largo camino que llevará a las mujeres del futuro a su completa liberación.

\section{LA MUJER TRADICIONAL: UN SER DEPENDIENTE Y SIN DERECHOS}

Con espíritu crítico, Leonor Espinoza de Menéndez pinta en Zarela la sociedad machista, retrógrada e intransigente de fines del siglo XIX y principios del XX, en los que la mujer no tenía prácticamente ningún derecho,

\footnotetext{
4 Minardi sostiene que Espinoza "se distancia de feministas más radicales encabezadas por Zoila Cáceres" y se acerca de la liberal Alvarado. Según la lectura de los ensayos y novelas de ambas escritoras, se induce que Alvarado presenta una visión mucho más revolucionaria que Cáceres.

5 Véase mi ensayo, "María Jesús Alvarado Rivera: primera feminista peruana" (Otoño 2007) en la Revista Canadiense de Estudios Hispánicos 32. 1, pp. 149-163.
} 
pero sí muchos deberes que la sometían a los designios de los hombres y de la familia. Prevalecía el modelo del "ángel del hogar", "de esposa o santa mujer", con belleza física y atractiva, pero sumisa a la autoridad varonil, mujer sin suficiente educación ni aspiraciones propias, consagrada por entero al marido $e$ hijos, y recluida al ámbito privado de su casa; un ser totalmente dependiente del padre, del esposo o del tutor, los que decidían su destino sin tener en cuenta su opinión ni sus deseos. Esta situación de sometimiento lo legitimaba el Código Civil, cuyas leyes anacrónicas e injustas consideraban a la mujer como un ser inferior y sin derechos jurídicos a la que la Iglesia y la sociedad predicaban renuncia, sacrificio, silencio y sumisión.

La feminista Cáceres en 1909 describe la preocupación de las mujeres por la belleza externa sobrevalorada por las familias, los hombres y la sociedad en su conjunto. Cáceres compara a las argentinas de las peruanas $y$ nota un gran desequilibrio en cuanto a la psicología, porque mientras las primeras logran autonomía y estudios, las peruanas siguen inseguras y dependientes. Ese lavado de cerebro a través de la domesticación cultural y social se traduce en la novela de Espinoza a través del personaje Olga que dice convencida, "Las niñas deben ser buenitas, humildes $i$ saber perdonar el daño que se les hace, para que Dios las bendiga i sean felices" (Espinoza M, L. ¿1915? p. 12). No deja espacio para la autodefensa o la resistencia frente a los seres que las agreden o castigan. Asimismo, debido a la limitada educación que recibía, la mujer no estaba preparada para insertarse en el mundo laboral o profesional, y quedaba totalmente desprotegida frente a posibles contingencias, cuando fallecían sus padres o esposos y quedaban libradas al tutor o al marido en los casos en que ellos la violentaran y abusaran de sus fondos económicos.

La sociedad peruana consideraba que la mujer poseía escasa habilidad racional y destreza para desempeñarse en actividades públicas que se realizaban fuera de la esfera del hogar. Asentaba sus prácticas discriminatorias por medio de prejuicios sexistas y biológicos infundados que esgrimían sus organismos, el político del Estado y el científico de ciertos intelectuales. Algunos pseudos científicos apoyaban la teoría de la inteligencia inferior a la del hombre, debido a que la masa encefálica de la mujer era menor que la masculina. En la mayoría del discurso de la época, los hombres reducían a la mujer a "un bello bípedo de encantadora cabeza vacía" (Espinoza M, L. ¿1915? p. 51), o a un mero objeto sexual del que se servían a su antojo. En ese entorno de discriminación oficial, la mujer no tenía otra opción que resignarse a un matrimonio por conveniencia o a refugiarse en el claustro de un convento. También debía soportar la maledicencia y la difamación de una sociedad hipócrita e intolerante que no perdonaba el menor desvío a su código moral rígidamente dualista y establecido por la sociedad para beneficio de los hombres.

Según las arcaicas leyes del Código Civil las mujeres en general $y$, en especial, las madres estériles, las madres monoparentales y las viudas sin hijos no podían administrar su fortuna ${ }^{6}$. Por medio de sus personajes femeninos, la escritora Espinoza plantea las diferentes situaciones que debía enfrentar la mujer en el Perú de la última mitad del siglo XIX y principios del XX. Uno de ellos, Luisa de Espanet, encarna a la aristocracia limeña que pierde su patrimonio $\mathrm{y}$, como no está preparada para afrontar la vida, decide casarse por interés con un hombre rico mucho mayor que ella. Con el fin de asegurar su fortuna y llenar el gran vacío afectivo de su existencia, se ilusiona con la maternidad; pero al no concretarse, llega hasta el extremo de fingir un embarazo, parte a Arequipa y compra una niña a un par de mujeres pobres que la tenían a su cuidado.

En la sociedad de entonces impera la intolerancia y la crítica mordaz frente al hecho de que Soledad Tomazi dé a luz a una hija

\footnotetext{
6 Sobre el asunto, Elvira García y García da el ejemplo de la escritora arequipeña, Manuela Ureta de Madueño, que al quedar viuda "vio desaparecer su fortuna y bienestar, que formaban el porvenir de sus hijos... por una gran estafa de que fue víctima" (57-58).
} 
previa al matrimonio con Raimundo Tassara. Éste prefiere ocultar el nacimiento de la hija porque el grupo condena a la madre con el mayor de los escarnios; de ahí que muchas otras mujeres se resignen a la pérdida o abandonen a los hijos. El temor a la deshonra impulsa a los padres de la niña Zarela a confiársela a dos mujeres necesitadas para que la críen hasta que ellos concreticen su unión. Cuando descubren la desaparición de su hija comprada por la limeña Luisa de Espanet, se afanan tenazmente en su búsqueda, aunque sin éxito. Tienen otras dos hijas, Soledad y Margarita, pero los remordimientos y la culpa que sienten por la pérdida de la primera hija terminan por minar su relación marital.

Al morir la madre de Soledad y Margarita, el esposo Raimundo concede la responsabilidad parental a su hermana soltera Hermengarda que cría a las dos niñas. El único afán de la tía era "atrapar novio buen mozo i de fortuna" (Espinoza M, L. ¿1915? p. 43). A través de este personaje, la autora pinta a las mujeres que cifran "toda su esperanza de felicidad i completo bienestar en el matrimonio" (Espinoza M, L. ¿1915? p. 41), y al no realizar su deseo, se deprimen y se sienten insatisfechas. Sin otras aspiraciones personales que den sentido a sus vidas, se convierten en meros satélites del hombre, sin cuya presencia y sostén no pueden sobrevivir. El discurso de Hermengarda sobre "la instrucción de la mujer ŚqueS no tenía objeto" (Espinoza M, L. ¿1915? p. 40), es elocuente de su mentalidad conservadora y atrasada que condena a sus sobrinas a una instrucción superflua y virtual ignorancia como lo exclama:

Un poco de Urbanidad que prestase el distintivo de señorita instruida. . . Algo de dibujo y pintura. . y un poquito de música. . . Un ligero conocimiento de corte, costura i cocina que pongan de manifiesto a la futura, económica i hacendosa mamá. ¿Para qué más? iCon todo esto se habían abarcado los grandes conocimientos para actuar brillantemente en sociedad! (Espinoza M, L. ¿1915? pp. 40-41)

El único fin de esa exigua educación femenina, consiste en atraer a un marido que le asegure su porvenir y empuje a la mujer a cumplir el rol tradicional de buena esposa y madre ejemplar. La manipulación verbal de Hermengarda no deja duda sobre su meta pragmática e inmoral: "no podemos contar para el porvenir con otra cosa que con el matrimonio y para conseguirlo pondremos en juego todos los medios, por ilícitos que parezcan. El ardid debe ser nuestra arma favorita" (Espinoza M, L. ¿1915? p. 45). En lugar de educar a sus sobrinas para que sean personas independientes y autosuficientes, las condena a un futuro de víctimas. Guiándose por las apariencias, favorece el noviazgo de su sobrina Margarita con Ruperto, un joven disoluto, ególatra y jugador, cuyo único deseo es divertirse.

Con su narrativa, Leonor Espinoza de Menéndez emprende una crítica acerba de la intervención de las madres o los familiares sustitutos que fomentan deliberadamente, primero, la vanagloria superflua de las jóvenes; $y$, segundo, el machismo en sus hijos, convirtiéndolos en hombres desconsiderados, egoístas y futuros tiranos de sus compañeras ${ }^{7}$. La interrelación entre las clases sociales, el poder económico y la cuestión de los géneros se manifiesta en los conflictos de la historia. Es el caso de la madre de Ruperto, que ciega frente a los defectos de su hijo y deseosa de que éste consiga una esposa rica y de familia distinguida, se opone terminantemente a su relación con la humilde Margarita y aprueba su conducta amoral cuando éste la abandona después de desflorarla, dejándola en cinta.

Es importante considerar los conceptos teóricos de Robert W. Connell que desarrolla en Gender and Power (1987) para entender de qué manera los personajes aceptan $e$ internalizan como normales ciertos aspectos de las relaciones sociales que se aprenden y que prescriben los roles de género. El primero es el

\footnotetext{
Al respecto léase, "Poniendo a cada quien en su lugar: estereotipos raciales y sexuales en la Lima del siglo XIX" de Patricia Oliart (1995) que señala "Otra importante función del estereotipo del limeño inútil, desvalido e irresponsable, era posiblemente disfrazar el poder real de estos hombres en su sociedad" (269).
} 
de "la masculinidad hegemónica" y el segundo su correlato, "la feminidad acentuada" que se refieren a las nociones dominantes e idealizadas de los comportamientos sexuales existentes en la sociedad. Si aplicamos a la novela peruana de Espinoza, podríamos convenir que las formas dominantes de la sexualidad masculina a fines del siglo XIX y principios del siglo XX, fueron el poder, la agresión, la invulnerabilidad, la razón y el control de sí mismo. Sus implicaciones en los otros sectores de la vida se manifiestan en el éxito laboral y financiero, público y familiar que determinan la dominación heterosexual de las mujeres, así como la suficiente distancia y oposición de las características femeninas que la cultura otorga a las mujeres. De manera correlativa, el concepto de la feminidad acentuada deriva de la masculinidad hegemónica, por lo tanto, pone el énfasis en el comportamiento de la mujer: emocional, nutricio, vulnerable, dependiente, sexualmente deseado y maleable. Estas idealizaciones estereotipadas de los géneros desembocan en los tradicionales papeles que limitan a la mujer a ser esposa, madre y la amante vista y considerada como un ornamento sexual.

La historia de la joven Margarita y el engatusador galán Ruperto pone en evidencia dichos modelos sexuales que señalan la intransigencia e injusticia de una sociedad impostora que condena a la mujer por ceder a los avances del amante y absuelve al hombre del comportamiento sexual irresponsable. La alocución de Soledad que le dirige a la tutora Hermengarda expresa, sin embargo las profundas contradicciones que resultan de la arbitraria situación que soportan tanto su hermana Margarita como las mujeres abusadas por Ruperto y los de su especie, señalando sobretodo la de su propia familia:

iTía!, usted es muy injusta con mi desgraciada hermana; como si ella sola fuese la culpable, contra ella son sus odios... ¿no halla usted culpabilidad en la conducta del seductor que aprovechando estados anímicos dolorosos i situaciones anormales, quita la honra i tranquilidad

\section{de una mujer?}

¿Por qué seguir esta rutinaria costumbre de condenar siempre al más débil de los que delinquen?

¿Es que inspira más conmiseración el criminal que empuja a su víctima hacia el abismo i no ésta que inconsciente $i$ presionada a él desciende? (Espinoza $M$, L. ¿1915? pp. 80-81)

Margarita expone de un lado, la construcción cultural y psicológica de los géneros que define y regula la sexualidad, la feminidad y la masculinidad de manera jerárquica al interior de la familia sin padres. La estructura social y hegemónica del patriarcado favorece el estatuto delincuente del hombre "seductor... criminal" cuyas acciones quedan impunes, y también propaga la ideología de su poder, abuso y superioridad. Justamente Bárbara, una profesora arequipeña que cree en la brujería, acepta lo que los europeos misóginos Moebius y Proudhon afirmaron "que los de sexo masculino poseen mayor capacidad cerebral que nosotras" (Espinoza M, L. ¿1915? p. 149). Mientras que a la mujer "víctima", el hombre -sea el esposo, amante o padre- la controla, humilla, castiga, insulta, brutaliza y condena. De otro lado, el discurso de Soledad devela la complicidad de Hermengarda en la crianza de las jóvenes. Después de haber empujado a su sobrina en los brazos del vil seductor Ruperto, la tía hace recaer toda la infracción del embarazo solamente en Margarita. La reacción ofensiva del padre de Margarita se semeja a la de Hermengarda; en vez de ayudar a su hija que espera criatura, él la considera muerta para la familia por haberse deshonrado y la abandona a su suerte. La joven Soledad que se da cuenta del juego de seducción masculina, de la doble deserción del padre y el amante, y del menosprecio de la tía que se abate contra Margarita, su desgraciada hermana, se compadece de ella, la defiende y trata de comprenderla. Sin embargo, como es otra mujer sin educación, la fatalidad también cae sobre su existencia.

Sin contar con el apoyo de una educación eficiente que le proporcione las armas para

\footnotetext{
8 La traducción del inglés al español es mía de "hegemonic masculinity" y "emphasized femininity".
} 
afrontar las vicisitudes de la vida o de un familiar que defienda sus derechos, Soledad se resigna a aceptar un matrimonio sin amor con el único propósito de asegurar su destino condenado a depender del padre o del marido. La narradora anota, "Ella, como la tía, buscó en ese enlace un asilo a su debilidad e ignorancia de noble i engreída" (Espinoza M, L. ¿1915? p. 102) mostrando las condiciones de precariedad de la casada y del próximo fracaso de una mujer de la clase media. El señor Raimundo Tassara, padre de Soledad se deslumbra por el dinero del futuro yerno Simón, y no duda en entregarle a su hija, circunstancia que provoca el derrumbamiento de las ilusiones de la tía Hermengarda, que aspiraba a ser la elegida. Ya casados, la desconsideración del hombre mayor Simón, sus aventuras extramaritales y el asalto sexual a la empleada Inés en su propia casa, del cual Soledad del Valle es testigo, terminan convirtiendo su matrimonio en una mascarada, ella lo califica de "esta ridícula comedia social" (Espinoza M, L. ¿1915? p. 109) del que sólo puede escapar por medio de la auto-muerte. El nombre simbólico de Soledad agrega una significación macabra a su estado determinista y trágico. El comentario del narrador subraya bastante bien como se mantiene la lucha implacable de los géneros en desventaja de las mujeres:

Perdida su individualidad i convertida en objeto de arte, comprado por su poseedor del seno de la familia i del seno de una sociedad egoísta e intransigente, debía permanecer allí, ocupando el puesto señalado entre los objetos de aquella casa, aunque el dueño hastiado de ella, la menospreciase.

No le quedaba más recurso que apelar a la fe implorando resignación; era mujer y debía sufrir las consecuencias de su sexo, la sociedad i el código estaban en contra suya;. . . el código civil con sus injustas leyes, estableciendo una profunda desigualdad en el matrimonio. (Espinoza M, L. ¿1915? pp. 112-113)

Antes de analizar el comentario de la narradora, debemos señalar que la aceptación social del doble estándar en lo que se refiere al comportamiento masculino agresivo $y$ conquistador en las relaciones sociales $y$ sexuales y a la posición femenina pasiva y victimaria, incrementa "el terrorismo psicológico" en las mujeres que lo padecen diariamente y engendra inevitablemente la coerción del macho y el miedo de la agredida. De acuerdo a Carole J. Sheffield en su estudio "Sexual Terrorism", "El derecho de los hombres de controlar el cuerpo femenino es la piedra angular del patriarcado... La violencia y su corolario, el miedo, sirven para aterrorizar a las mujeres y mantener la definición patriarcal de su lugar... Lo llamo terrorismo sexual porque es un sistema en el cual los machos asustan y, por medio del terror, controlan y dominan a las hembras." (Sheffield, C.J. 1994, p.) $)^{9}$

Teniendo en mente el aporte de Sheffielf, consideramos en primer lugar, el comentario discursivo de la novela que subraya el desvalor y la cosificación de la esposa frente al marido que la usa, abusa y desecha, manifestando la alienación femenina que aflige y expone todo el dolor y la angustia de una terrible realidad para la esposa. De manera frontal se mantienen estables el poder, la propiedad y los beneficios del hombre en su calidad de amo. En segundo lugar, destaca la forma en que se establece la institución social del matrimonio a través de la legalización jurídica del encadenamiento de las mujeres servidoras o esclavas en relaciones anómalas y asimétricas que favorecen al señor. En ese contexto de desequilibrio de poder, es prácticamente imposible que una mujer, como Soledad, que sufre en un matrimonio infeliz, se divorcie o se libere. Si se atrevía a hacerlo, no sólo enfrentaba la severa condena social, sino también la miseria. El doloroso desengaño de Soledad por las continuas humillaciones a las que la somete su marido y la obligación de seguir representando la farsa de un matrimonio avenido frente al inflexible juicio de la sociedad, resquebrajan su salud mental. El narrador hace la radiografía del perfecto hombre perverso y de la esposa dócil,

Simón, lejos de guardar alguna consideración a su infeliz compañera,

La traducción del inglés al español es mía. 
parecía alardear sus devaneos. Ya dejaba caer al descuido un pañuelito coquetón de mujer, ya quedaba un rizo de cabellos, o el billete comprometedor al alcance de la prudente i resignada Soledad... No obstante, ella persistiendo en el empeño de atraerle, hacíase gran violencia por dominar su justa indignación, redoblando en cambio mimos i prudencia. (Espinoza M, L. ¿1915? pp. 108-109)

La polaridad entre las actitudes del donjuanesco varón y su retórica que ofende verbalmente a la esposa, chocan y la empujan a Soledad a la desesperación y a reprimir todo gesto de resistencia o enfrentamiento. La terrible depresión que la conduce a pensar en la muerte $y$ encontrar finalmente cierta liberación, imposible de lograr en el casorio con un libertino, no aniquila sin embargo su espíritu solidario con la hermana Margarita abandonada por el violento Ruperto que "cobarde y alardeando villanía, la hería no sólo de palabras sino también de hechos" (Espinoza M, L. ¿1915? p. 135). Las diferencias entre ambas hermanas también permiten vislumbrar los arranques de rebeldía de Margarita frente a la violencia doméstica, ella desearía tomar en sus propias manos la restitución de su derecho a ser respetada como ser humano. Como la sociedad peruana no hace justicia a la mujer abandonada, de manera patética el narrador exclama tomando la posición de ambas hermanas deshonradas, una por el marido y la otra por el amante, "iCuántas lágrimas vertidas juntas! iCuántas violencias por domeñar los impulsos de venganza de la escarnecida víctima!" Luego Margarita le confía a Soledad, "-Si no fuera por ti -la decía- ya le habría castigado como se merece; por mí no temo nada, mi nombre hace tiempo borrado está del pedante libro social, nadie tendrá en cuenta a la infeliz que un miserable sumergió en el barrizal de la deshonra... ¿Acaso no crees que el débil brazo de una mujer, no puede herir cuando a éste la guía el de la justicia?". Sin embargo, ese arranque humano y natural de Margarita de castigar a su ofensor o que repare el engaño sexual, es frenado por la hermana Soledad que tiene una conducta más conservadora y vive amedrentada por "las inconveniencias de aquellos impulsos” (Espinoza M, L. ¿1915? pp. 116-117).

La situación degradada de Margarita traduce el panorama negativo de la sociedad peruana. La madre soltera y abandonada por su familia y por el amante violento, necesita velar por su pequeña hija y se aferra al último recurso que le queda, el trabajo; pero al no haber sido instruida en ninguna profesión $u$ oficio retribuido, sólo puede dedicarse a la costura, "único recurso de las desheredadas; único trabajo medianamente decoroso $i$ pésimamente remunerado con el que debe vivir en este país una mujer honrada;. . . obteniendo como recompensa la tuberculosis i otras dolencias físicas" (Espinoza M, L. ¿1915? p. 137)..$^{10}$ Inmediatamente agrega que "no le quedaba otro recurso que coser, coser aquella burda costura de mercado con la cual ganaría treinta céntimos en catorce o quince horas de rudo i fatigoso trabajo! (Espinoza M, L. ¿1915? p. 138). A las condiciones precarias y de explotación laborales se suma el maltrato de la sociedad. Margarita soporta tanto las vejaciones y "groseras propuestas" de algunos hombres que la creen una presa fácil por hallarse en la miseria; como los desprecios de mujeres que la ven como una amenaza por su belleza y juventud. Al respecto no llama la atención que Margarita recuerde la segunda estrofa del largo poema social "La ramera" del liberal mexicano Manuel Acuña (1849-1873) que pinta exactamente cómo se siente la joven peruana,

iPobre mujer! que abandonada y sola sobre el oscuro y negro precipicio, en lugar de una mano que la salve siente una mano que la impele al vicio; y que al fijar en su redor los ojos

10 En varias obras de la época, las escritoras denuncian las condiciones inhumanas de las trabajadoras de la costura y las labores que se asocian, como el tejido, el crochet y el bordado. Una de las primeras en desenmascarar la opresión de las mujeres fue María Jesús Alvarado Rivera que en El Feminismo expresó, "Sólo dos caminos tiene la mujer en tan premiosas circunstancias los ímprobos trabajos manuales que no libran de la miseria con su pavoroso cortejo de martirios y humillaciones, o el deshonor a cambio de un aleatorio bienestar." 
y a través de las sombras que la ocultan no encuentra más que seres que la miran y que burlando su dolor la insultan...

¿Sabría Margarita que su poeta preferido que, denunció la crueldad del medio social hacia la mujer necesitada de consuelo, propuso que el ser humano podía liberarse por medio del estudio y las ciencias? ¿Tal vez la sensible lectora Margarita emuló el fin trágico de ese filósofo positivista e incrédulo que angustiado no halló respuestas a sus preocupaciones y se suicidó en plena juventud?

Margarita adolece de "decaimiento moral" por "las amenazas... los insultos i escarnios" de los acreedores, pero impulsada por la hambrienta hija, acude a un convento que reparte el alimento a los miserables de Arequipa. Una mujer que la contempla, llega a insinuarle que le saque partido a su belleza y se dedique a la prostitución "único refugio que ofrece nuestro estado social a una pobre que no conoce ni sabe nada útil para ganarse la vida honradamente" (Espinoza M, L. ¿1915? pp. 170). Cuando Margarita le contesta: “-iHorror, no, mil veces no!, su interlocutora le recita el parlamento dramático de la obra teatral en tres actos y en verso, La Pasionaria (18831884) del autor español realista, Leopoldo Cano y Casas (1844-1934), del personaje Petrilla que se asemeja por su condición desvalida a la madre soltera peruana, porque la española también pide caridad para su pobre hija Margarita que no conoce a su padre:11

- ¿Adónde vas?

- Donde pueda, donde va lo que zozobra

lo que expira, lo que sobra, lo que vaga i lo que rueda;

al asilo, a la prisión,

al templo o al lunapar,

al abismo o la montón!

La intertextualidad de la que se vale la novelista peruana, sirve para notar que tanto en España como en Perú, existieron literatos que se preocuparon por denunciar el esclavismo y la dependencia total y financiera de las mujeres y levantaron su voz de protesta. Con las enumeraciones poéticas de las acciones trágicas de la persona atormentada por los problemas, tanto los verbos como los lugares del parlamento de Petrilla explicitan el desamparo total de la madre soltera desde el punto de vista social, económico y psicológico, pero también apunta a la degradación final como un callejón sin salida en el que la comunidad a las que pertenecen, las condena "al abismo". A partir de la reflexión de los versos, el narrador peruano presenta a Margarita con su "terrible dilema: escoger el camino de la corrupción para salir del atascadero pecuniario en que se encuentra o seguir por el oscuro i misterioso de la muerte... Pecó por amor no por vicio. iAh! Mil veces cadáver, antes que despreciable muñeca de placer..." (Espinoza M, L. ¿1915? pp. 171-172).

La sociedad acorrala a la víctima vencida entre la degradación física o la muerte. La imagen de la mártir "la impelen al sacrificio." Después de una angustiosa meditación frente a la disyuntiva, Margarita decide desaparecer y arrastra a su inocente criatura a las frías aguas del río Chili sabiendo que nadie la apoyará. El símil que usa la escritora arequipeña, "i cual la poetisa de Mytilene en el promontorio de Leucales, abrazada a su tierna lira se arroja con vertiginosa rapidez en el abismo!... (Espinoza M, L. ¿1915? pp. 176), pone en la tradición clásica griega, el heroísmo desesperado de personajes femeninos que solamente en el suicidio logran liberarse de la existencia, sus cadenas, injusticias, indiferencia y condenas.

¿Se puede afirmar que el suicidio de la madre monoparental junto a su niña es el punto culminante del menosprecio social peruano y el síntoma de la familia indolente que andaban enfermos bajo el peso de tradiciones retrógradas, prácticas misóginas y necesitaban una metamorfosis fundamental de la mentalidad y legislación

\footnotetext{
11 La obra del español fue conocida en América y en Perú. Sería interesante trazar un estudio comparativo de la novela peruana y del drama español para establecer la influencia que tuvo Cano en Espinoza, al menos en las personalidades de Petrilla y Margarita como en su condición social de madres solteras y abandonas.
} 
que facilitaran el fin del abuso cotidiano y la restauración de la justicia social? La maternidad en lugar de considerarse una función social ennoblecedora para la madre soltera se convierte en un baldón familiar y una desgracia nacional. De manera contradictoria, de un lado, el discurso patriotero encomia a la mujer por su capacidad de engendrar la prole que servirá al desarrollo y futuro de la nación; pero de otro lado, condena y discrimina a la madre soltera, sin darse cuenta que la tragedia de Margarita no es un caso aislado y que representa la situación de un sector social marginalizado al interior de la nación. El drama familiar de Margarita que se lanza al abismo es también el drama de la gran familia nacional del Perú cayendo en desgracia.

De modo paralelo, al terrible sino de las dos sobrinas en relaciones amorosas $y$ matrimoniales desdichadas, la condición de su tía Hermengarda presenta la otra opción tradicional para las mujeres. Desencantada de su papel de victimaria y sin gozar de fortuna propia, decide refugiarse en un convento para protegerse de la soledad y la miseria. Sin embargo se vuelve loca en el encerramiento con la obsesión amorosa de un hombre que no la amó. El lector contemporáneo se pregunta, sin educación que provea la preparación para trabajar y valerse por sí misma, ¿qué otra alternativa le quedaba a la mujer casada y a la soltera para sobrevivir de manera autónoma y digna?

Las historias macabras de estos personajes femeninos comparten el desamparo y la dependencia de las mujeres en una sociedad discriminatoria en la que predominan las desigualdades de género, el maltrato físico, verbal, psicológico y mental al interior de las parejas. Careciendo de una educación sólida que las sustente en el duro camino de la existencia, sus opciones se limitan a un matrimonio por compromiso y sin amor, a la reclusión en el claustro, a prostituirse o, lo que es aún peor, a la misma muerte. Frente a este cuadro patético y desmoralizador del Perú novecentista, de acuerdo a la novelista Espinoza, ¿qué vía le queda a una joven inteligente y empeñosa para ser dueña de sus decisiones, forjarse su propio destino y liberarse de las cadenas que le imponen las familias, las creencias tradicionales, las vetustas leyes y la nación patriarcal? Mediante la estrategia de la oposición radical entre las víctimas de una fatalidad asombrosa y una protagonista feminista que decide valerse por ella misma, Espinoza indica un nuevo camino a construir para las mujeres del Perú.

\section{LA MUJER MODERNA QUE ABOGA POR LA IGUALDAD DE DERECHOS Y LA NECESIDAD DE EDUCACIÓN}

Justamente en la novela de Espinoza de Menéndez aparece un personaje que encarna el modelo de la mujer moderna y culta que adopta y favorece la educación femenina y su independencia financiera. En efecto, la protagonista arequipeña Zarela, la otrora niña que fue comprada por Luisa de Espanet muchos años atrás, ilustra el ser nuevo que se apoya en sus propias fuerzas y capacidades mentales para salir adelante. Desde su más tierna infancia, Zarela manifiesta su anhelo ferviente de ilustrarse $\mathrm{y}$, a pesar de las objeciones de su madre que cree que una hija de su posición social acomodada no necesita del estudio, Zarela no desiste en su propósito de educarse y explorar su potencial mental. No contentándose con terminar la educación media, algo poco común en las mujeres de fines del siglo XIX, insiste en ingresar en la escuela de medicina, ámbito exclusivamente masculino. En ese medio de poder, soporta las burlas y los avances amorosos e inmorales de algunos compañeros, pero su seriedad, competencia intelectual y sentido de responsabilidad le granjean el respeto y la admiración de otros estudiantes y profesores.

Al descubrir la verdad sobre su nacimiento por medio de Rosalía la criada moribunda de su madre, Zarela insiste en conocer a su familia biológica y, junto a su madre adoptiva, viaja de Lima a Arequipa. La amarga verdad le salta a la cara, su madre y sus hermanas han muerto, su tía entró en un convento y su padre huyó a otro país. A través de los diarios de sus hermanas, se entera de las angustiosas tribulaciones que ellas soportaron. Indignada 
frente a "la triste condición social de la mujer peruana" jura "trabajar incansable en pro del feminismo, por la justa liberación de la mujer" (Espinoza M, L. ¿1915? p. 181). El narrador condensa los ideales y las convicciones feministas de Zarela en el siguiente párrafo:

Zarela aboga por la igualdad moral de sexos, igualdad redentora $i$ símbolo de prosperidad. Invita a la mujer que dejando a un lado rancias preocupaciones i orgullos. . ., adquiera útiles conocimientos para que... pueda ejercerlos, sirviéndose en cualquier emergencia desgraciada. Ridiculiza el menosprecio que del trabajo hace la engreída nobleza. - Señala como causa primordial de muchos males que afligen a la sociedad, la insuficiente i defectuosa educación femenina. Pide que esa sociedad permita a la mujer ocupar el lugar que el progreso le señala, para que ésta adquiera el perfecto conocimiento de su valer i derechos, vedados por tan largo tiempo por el error, atraso i egoísmo. (Espinoza, $M$, L. ¿1915? pp. 183-84)

Primero, Zarela concede el primer valor a la equidad educativa, ética y sexual sin las cuales las mujeres no podrán emprender su desenvolvimiento personal ni hacer que los centros de enseñanza avalen sus estudios. En segundo lugar, señala el trabajo como fuente de desarrollo individual y nacional, y critica severamente la actitud de la aristocracia ociosa. En tercer lugar, enjuicia la educación vigente solamente para los hombres porque aísla y margina a las mujeres, origina las discriminaciones, los conflictos sociales y esboza la necesidad de su completa evolución. Como resultado, finalmente, si se logran los objetivos anteriores, la mujer saldrá del espacio reducido en el que la han colocado los padres de familia, los organismos del estado, las autoridades espirituales y económicas. Por eso destaca la única manera de luchar contra "el error, atraso i egoísmo" si la mujer accede al "perfecto conocimiento de su valer i derechos."
Espinoza compone de manera feminista a su joven $e$ intelectual protagonista. La visión equitativa de Zarela se concretiza en infinidad de obras comunitarias, tales como las sociedades feministas, las escuelas para la mujer, los asilos, los bazares que venden las labores femeninas, y otros organismos. Ella misma constituye el mejor ejemplo de lo que predica, ya que al perder su madre toda fortuna, Zarela sostiene a su familia gracias al fondo financiero que adquiere de su profesión científica. De la misma forma, por medio de la prensa y de conferencias, brega sin cansancio por "la reforma en las leyes para que pueda establecerse así la equidad e igualdad de sexos" (Espinoza M, L. ¿1915? p. 188). Zarela rompe con la dicotomía entre el ámbito privado, al que se recluía a las mujeres, y el ámbito público exclusivo de los hombres. Frente a la dura oposición que despiertan sus ideas en el seno de los sectores más conservadores de la sociedad. Se menciona a mujeres y hombres profesionales que la critican, como el astrónomo Pedro Alcázar y el entomólogo Benito Peñaloza quienes la ven como un peligro, porque ellos piensan que a causa de las proposiciones femenistas de "la mujer moderna, perecerán nuestros derechos" (Espinoza M, L. ¿1915? p. 189). No obstante, Zarela contemporiza en parte con ellos con el fin de atraérselos a su causa, pero sin ceder en lo esencial de su prédica:

Tengan la convicción que la mujer moderna continuará siendo la compañera amante i sumisa del hombre; pero más espiritual i consciente de su valer i derechos, así como más idónea para desempeñar los deberes augustos de madre, educadora, i miembro útil de la sociedad.

Lo único que nosotras pretendemos es que se considere a la mujer igual y compañera del hombre en la verdadera acepción de la palabra; no su inferior, esclava, o maniquí de sus caprichos i pasiones. Deseamos que del hogar desaparezca aquella paria que, con nombre de esposa o santa mujer, soporta borreguilmente todas las villanías i humillaciones del más inicuo 
despotismo. (Espinoza M, L. ¿1915? pp. 192-193)

A través de su personaje principal, Leonor Espinoza de Menéndez propone a Zarela, que proyecta el futuro de una mujer liberada e independiente, considerada por sus esfuerzos y voluntad, capacidades intelectuales y su desempeño social igual al hombre; aunque llame la atención que la propia Zarela arguya que la mujer consciente siga siendo "sumisa" al esposo. La ideología dualista tan inserta en la mayoría de escritoras del novecientos, se presenta también en la feminista Espinoza, ello les impide concebir una relación equitativa entre hombre y mujer. Sin embargo, la representación de la mujer nueva se encuentra en la antípoda de la mujer tradicional considerada, "inferior, esclava, o maniquí" del hombre que no protesta ni sabe como hacerlo para romper ese ciclo infernal que la aniquila.

El título de la novela Zarela. Una historia feminista, apunta a una meta reivindicativa que nacía en la región sur del Perú y el aporte de la escritora arequipeña significa un gran progreso y avance ideológico para el movimiento feminista, porque aborda la lucha por la igualdad de los géneros, explora los ámbitos educacional, social, jurídico, familiar, económico y psicológico que configuran y soportan las ideologías prejuiciadas y los discursos sexistas de una época muy atrasada y machista.

\section{A MODO DE CONCLUSIÓN}

En su novela Zarela. Una historia feminista, Leonor Espinoza de Menéndez contrapone a la triste realidad de las mujeres ignorantes $y$ sometidas al padre cruel o indiferente $y$ al marido abusivo y tirano, un modelo de la mujer moderna, instruida, independiente y feminista. Con fuerza narrativa, la autora denuncia las desigualdades de género y de sexos, las vejaciones infligidas a las mujeres, los prejuicios y las convenciones socio-culturales del Perú de fines del siglo XIX y albores del XX. Mediante Una historia feminista Espinoza postula el movimiento progresista del feminismo que exige la independencia económica de las mujeres, su derecho a educarse, adquirir una profesión, a trabajar y a ser autónoma, de esa forma se intenta implementar la igualdad moral de ambos seres. A pesar de que denuncia el sistema del Código civil que legaliza la inferioridad de la mujer, la equidad de derechos no abarca el ámbito político ni ciudadano que significaría una garantía más de los cambios en la sociedad; por eso su feminismo se muestra moderado y reformista.

La novela de Espinoza contiene una primera propuesta feminista y literaria crítica que cuestiona los patrones masculinos y femeninos sobre los géneros y los sexos, y constituye un importante eslabón en el largo proceso que llevará a la mujer a adquirir su completa igualdad e independencia en Arequipa, la nación del Perú y en el mundo entero.

Este inicial y fuerte impulso literario y feminista que propugna el respeto de los derechos básicos de la mujer a la educación y al respeto de su existencia, narra las relaciones desiguales de poder al interior de los hogares peruanos de clases media y pobre en un contexto histórico nada favorable a la justicia sexual, equitativa, laboral y social. Sin embargo, el personaje Zarela, que se rebela contra los códigos restrictivos del Perú, adquiere formación científica y opta por conciliarla con el matrimonio casándose con el médico y poeta limeño Rafael Logaret, demostrando que al interior de una capa social, instruida y acomodada, se podía afirmar la inteligencia de la mujer que, cuando las condiciones la favorecían, ocupaba una plaza dentro de la sociedad con la que colaboraba valiéndose del trabajo y la independencia financiera ${ }^{12}$. El deseo de los amigos Peñaloza y Alcázar a la joven pareja sintetiza la conclusión dichosa de la novela y el mensaje de la escritora arequipeña, "iBienandanza $i$ prosperidad al feminismo razonable!”, (Espinoza M, L. ¿1915? p. 204).

12 Es posible que la batalla de la escritora Espinoza para educar en la universidad a sus hijas en Arequipa sin lograrlo, haya sido un móvil para la construcción de su personaje Zarela en Lima que a través de la novela puede realizar su proyecto, como lo hicieron las jóvenes Menéndez. 
La narrativa de Leonor Espinoza de Menéndez, cirujana diestra de la historia de las contemporáneas de su tiempo, constituye un gran avance feminista en contra de la ideología discriminadora, basada en estructuras dicotómicas de poder que impidieron el florecimiento de la mayoría de las mujeres, marginadas en los bordes de una nación llamada republicana. Queda todavía por estudiar los artículos y los cuentos que publicó la autora, tanto en Arequipa como en Lima, para completar su aporte a las letras peruanas y al movimiento del feminismo ${ }^{13}$.

13 "En el concurso provocado por la sociedad "Entre nous", para las fiestas centenarias de 1921, la señora de Menéndez, presentó un interesante cuento, que mereció una distinción honrosa, asegurando los críticos que reunía excelentes cualidades de amenidad, cultura y estudio profundo del corazón de la mujer" (García y García, 1925, p. 148). 


\section{REFERENCIAS}

Alvarado, M. J. (1912) El Feminismo. Lima: Imprenta de la Escuela de Ingenieros de Lima.

Cáceres, A. (1909) Mujeres de ayer y de hoy. Paris: Garnier Hermanos.

Cano y Casas, L. (2006) La Pasionaria. Revista Esticomitia. http://parnaseo.uv.es/ars/esticomitia/ numero4/sticho4/TEXTOS/PASIONARIA/La_Pasionaria_1.pdf

Connell, R W. (1987)Gender and Power. Stanford, CA: Stanford University Press.

Denegri, F. (1996) El abanico y la cigarrera. La primera generación de mujeres ilustradas en el Perú. Lima: Flora Tristán.

Espinoza de Menéndez, L. (¿1915?) Zarela. Una historia feminista. Arequipa: Tip. Franklin,n. d.

García y García, E. (1925) La mujer a través de los siglos. Serie historiada de estudios y observaciones. Lima: Imprenta Americana, Tomo II.

Guardia, S. B. (Mayo 2013) Imaginar la mujer. Mercedes Cabello y la educación femenina. En CEMHAL, Revista historia de mujeres. Lima, vol. 14, № 150. Disponible en Internet. http:// webserver.rcp.net.pe/cemhal/revista3.html.

Mataix, R. (2003) La escritura (casi) invisible. Narradoras hispanoamericanas del siglo XIX Universidad de Alicante 16. Disponible en Internet

http://rua.ua.es/dspace/bitstream/10045/7269/1/ALE_16_02.pdf.

Minardi, G. (2001) La narrativa femenina en el Perú del siglo XX, Alba de América, Vol., № 20. 37-38, pp. 177-196.

Oliart, P. (1995) Poniendo a cada quien en su lugar: estereotipos raciales y sexuales en la Lima del siglo XIX, Mundos interiores. Ed. Panchifi, Aldo \& Felipe Portocarrero. Lima: Universidad del Pacífico, pp. 261-288.

Rojas Benavente, L. (2007) María Jesús Alvarado Rivera: primera feminista peruana, La Revista Canadiense de Estudios Hispánicos 32. 1, pp. 149-163.

Rojas Benavente, L. (2010) "La educación de la población femenina del Perú, la demografía y la prostitución”, Canto poético a capella de las escritoras peruanas de 1900 a 1960. Lima: Editatú Eds. pp. 74-99.

Tauzin-Castellanos, I. (1999) Zarela: La emergencia del feminismo en Arequipa, Mujeres y género en la historia del Perú. Margarita Zegarra F. Ed., pp. 331-346.

Tauzin-Castellanos, I. (2004) La educación femenina en el Perú del siglo XIX, Aurora Marrou Roldán, Ed. Historia de la educación peruana y latinoamericana. Lima: UNMSM, pp. 92-102.

Villavicencio, M. (1992) Del silencio a la palabra. Mujeres peruanas en los siglos XIX-XX. Lima: Flora Tristán. 